\title{
LA ESTÉTICA POSMODERNA EN EL CINE: UNA APROXIMACIÓN TEÓRICA
}

\author{
POSMODERN AESTHETICS IN CINEMA: A THEORETICAL APPROACH
}

Galo X. Vásconez-Merino ${ }^{1}$

Francisca A. Carpio-Arias ${ }^{2}$

\section{Resumen}

La posmodernidad surge como contraposición al pensamiento moderno que manifestaba su exaltación a la razón, optimismo racionalista e inclinación por sistemas de metarrelatos. La perspectiva posmoderna se torna en una imagen pesimista y crítica de la sociedad, que se vislumbra como la deconstrucción de la razón. En el ámbito cinematográfico, la posmodernidad también hizo mella, tomando como iniciativa los mismos parámetros que la conformaban: critica de la razón e inclinación por la dispersión, lo múltiple y lo fragmentario. Es un nuevo enfoque que se inclina por la sensibilidad hacia la diferencia, la pluralidad y la exaltación de la subjetividad e individualismo. El presente artículo de reflexión realizará un recorrido por las características del paradigma posmoderno y su aplicación en la cinematografía en cuanto a la deconstrucción de la razón, muerte del sujeto, fragmentación e intertextualidad.

\section{Palabras clave}

Cine, Posmodernidad, Intertextualidad, Comunicación.

\begin{abstract}
Postmodernity emerges as a contrast to modern thought that manifests its exaltation to reason, rationalist optimism and inclination for metarelate systems. The postmodern perspective becomes a pessimistic and critical image of society, which is seen as the deconstruction of reason. In the cinematographic field, postmodernity also made a dent, taking as an initiative the same parameters that formed it: criticism of the reason and inclination for dispersion, the multiple and the fragmentary. It is a new approach that leans towards sensitivity towards difference, plurality and the exaltation of subjectivity and individualism. This reflection article executed a tour of the characteristics of the postmodern paradigm and its application in cinematography in terms of the deconstruction of reason, death of the subject, fragmentation and intertextuality.
\end{abstract}

\section{Key Words}

Cinema, Postmodernity, Intertextuality, Communication.

\footnotetext{
${ }^{1}$ Universidad Nacional de Chimborazo (Ecuador). Correo electrónico: gvasconez@unach.edu.ec

${ }^{2}$ Instituto Superior Tecnológico José Ortega y Gasset (Ecuador). Correo electrónico: antito084@hotmail.com.
} 


\section{Introducción}

La tesis que moviliza la presente investigación es la siguiente: La posmodernidad con su imagen pesimista y crítica de la sociedad ha dado paso, en su construcción narrativa cinematográfica, a parámetros perfilados en la deconstrucción de la razón, inclinación por la dispersión, lo fragmentario y lo intertextual.

Téngase en cuenta que la posmodernidad nace aproximadamente a mediados del siglo $\mathrm{XX}$, como una contraposición a las propuestas instauradas por la modernidad, "tenemos que afrontar una realidad de desorden, tanto en la regulación social como en la emancipación social. Formamos parte de sociedades que son autoritarias y libertarias al mismo tiempo" (Sousa, 2005, p. 98). La modernidad es una categoría que está conformada en torno a la razón, "optimismo racionalista, tiempo de teorías y sistemas" (De la Rosa, 2000, p. 56), en los cuales el pensamiento se moviliza por la idea de que todo puede ser conocido: es el culmen de la ilustración. "La modernidad puede ser catalogada como la afirmación de que el hombre es lo que hace, por el despliegue de la ciencia, la técnica y la administración al servicio de la producción" (Carretero, 2000, p. 34).

Friedrich Nietzsche, con sus postulados y principios filosóficos, es uno de los primeros en dudar acerca de los términos en los que opera la modernidad, "el nihilismo ocurre en la medida en que el hombre abandona el centro y se coloca en un punto cualquiera; cuando tiene lugar la desvalorización de los valores supremos" (Ramírez, 2005, p. 110). Cuando se cuestionan las verdades absolutas, se inscribe en un nuevo tipo de pensamiento. Nietzsche lo llamaba la muerte de Dios, "cuando la experiencia pierde la autenticidad y se emancipa de cualquier valor último" (De Carvalho, 1994, p. 14). Martin Heidegger declara que el Ser no es la Verdad, sino el verdadero objeto de la filosofía, "en la actualidad el humanismo se halla en crisis precisamente porque ha sustituido a Dios por la humanidad en el centro del universo" (Ramírez, 2005, p. 110), para él, "la forma de avanzar requiere reconciliarse con nuestra condición: ni la metafísica, ni el humanismo ni la tecnología pueden constituir bases sólidas para la vida" (Lyon, 1996, p. 26).

Lyotard indica que existen tres condiciones del conocimiento moderno: "el invocar a metanarraciones para legitimar el reclamo fundamentalista, el inevitable resultado de legitimación, deslegitimación y exclusión y un deseo por homogéneas y morales prescripciones" (Best y Kellner, 1991, p. 45). La modernidad hermana con ilaciones positivistas, que ponen en el centro la capacidad de la razón como única fuente de conocimiento, en detrimento de otros aspectos configurativos de las sociedades y el ser humano, que resultaron nefastas en diversas ocasiones. El desencanto por este tipo de normas sociales provocaría el aparecimiento del pensamiento posmoderno. Lyotard acota:

La posmodernidad representa el fin de la modernidad o el fracaso del proyecto moderno. Esta perspectiva es una imagen pesimista y crítica de la sociedad. La modernidad se consideraba altamente racional y rígida, mientras que la postmodernidad parece más irracional y flexible (Lyotar, 2004, p. 48).

Según Vattimo (1990, p. 9), "hablamos de postmoderno porque consideramos que, en algún aspecto suyo esencial, la modernidad ha concluido". Quienes se piensan a sí mismos como posmodernos pueden considerar "falsa la idea de progreso y, por tanto, no se postulan a sí mismos como superadores de la modernidad, simplemente aparecen después de ella” (González, 1991).

Esta nueva etapa posmoderna es considerada una desilusión de todo el saber que generó la teoría más el dogma, la cientificidad y la ética conductista, "las ideologías y sus construcciones consecuentes (las utopías), los paradigmas del racionalismo modernista: la sociedad sin clases del marxismo, la teoría crítica de la comunicación, el bienestar de las naciones, la igualdad de todos los hombres" (Carenzo, 2005, p. 59).

Para Lipovetzky, la posmodernidad significa la revolución del individualismo, "un nuevo estadio histórico en el que han entrado ya las sociedades democrático-capitalistas avanzadas y que se caracteriza por el vaciamiento o pérdida de sustancia de los ideales proyectados durante la época moderna" (Ros Cherta, 2011, p. 128). La sociedad pasa a desapropiarse de su elemento societal y da prioridad a las elecciones personales y al cumplimiento de la satisfacción personal, elementos cuestionados por su superficialidad y por dar un aspecto esteticista al capitalismo.

De la Rosa (2000, p. 56) señala que "la sociedad postmoderna no tiene ni ídolos ni tabúes, ni imágenes gloriosas de sí misma, ni proyecto movilizador alguno. Está regida por el vacío, un vacío que no comporta ni tragedia ni apocalipsis. El encanto de estar desencantados". La reflexión sobre el entorno se amplía, existe despojo de ideas totalizadoras y surge la multiplicidad de ideas en todo sentido.

Frente a una lógica férrea y unívoca, es necesidad dar libre curso a la interpretación; frente a una política monolítica y vertical de partido, la necesidad es apoyar a los movimientos sociales trasversales; frente a la 
soberbia de la vanguardia artística, la recuperación de un arte popular y plural; ésta es una visión mundial de las culturas (Vattimo, 2006, p. 47).

Vattimo sugiere que la posmodernidad es el paso de un pensamiento fuerte a uno débil, rechaza una fundación única, última, normativa (Vattimo, 2006, p. 43). La razón como fin ulterior deja de ser el pensamiento preponderante, las verdades absolutas se dejan de lado y este rechazo genera una nueva amplitud de miradas, capaces de adaptarse a las realidades y a la actualidad.

Mediante el siguiente estudio, se pretende hacer una revisión de los autores antes expuestos junto a otros que la cuestionan pero que no la suprimen o niegan, pues existe toda una corriente que habla de la posmodernidad como una modernidad tardía o una nueva etapa moderna. En el ámbito del cine, se abordan ejemplos de filmes que a partir de los años 80 han enfocado su creación sobre las bases ideológicas de la posmodernidad y que, a partir de ello, configuran su narrativa, unas veces como grandes aciertos y otras no tanto, pero que sirven perfectamente para ejemplificar aspectos puntuales de la posmodernidad.

\section{Referente teórico}

\subsection{El camino hacia el cine posmoderno}

El cine clásico tuvo lugar en las primeras décadas del siglo XX. A medida que se realizaba cada película, se divisaban avances tecnológicos, teóricos y audiovisuales y se configuraba un lenguaje propio. La narrativa se disparó en distintas entidades llamadas géneros, que "permitió a cada estudio especializarse y contribuir con sus conocimientos genéricos a la producción fílmica general" (Aumont, 1995, p. 19).

Bordwell designa al cine clásico como narración clásica (1996, p. 157), Casetti y Chio lo llaman narración fuerte (1991, p. 210), y manifiestan que en este relato existe un protagonista con un carácter definido, que tiene un objetivo por cumplir y metas diseminadas a lo largo del metraje y el espectador obtiene complacencia al ver que esos objetivos son cumplidos.

En años 60, el cine moderno genera un avance y una ruptura en cuanto a la tradicionalidad del cine clásico, "el concepto y la teorización acerca del significado del cine de autor nació hacia la mitad del siglo XX en Europa y propició una nueva manera de ver al cine y de valorarlo" (Gutiérrez, 2014, p. 3). Fue, en cierto sentido, un respiro entre toda la parafernalia de Hollywood, pero que al no plantear temáticas tan universales o ser tan transgresoras, no se ganaron un gran nicho como para ser éxito de gran cantidad de espectadores, por lo que poco a poco este cine quedó relegado a las salas de cine de arte y ensayo que, por otro lado, se mantienen gracias a un público asiduo y fiel.

El cine de ciertos directores pasa a ser catalogado como cine de arte o cine de ensayo, con un protagonista de personalidad ambigua, insatisfecho con la vida y apático con los conflictos que se le muestran, "esta narración no produce una proyección idealizada del espectador en los films, sino lo contrario, una confrontación con la realidad humana más cruda pero más real, la vida no es perfecta" (Gutiérrez, 2014, p. 8). El cine moderno configuró nuevas narrativas con el objetivo de romper todo canon previo mediante la experimentación, objetivo que también poseían las vanguardias artísticas y que terminó por llegar al cine. "Las vanguardias artísticas consideraron la técnica y la industria como los conceptos protagonistas de una nueva etapa en la historia del arte, propiciando así la necesidad de volver a definir el perfil del artista" (Sangro, 2016, p. 70).

Una vez que el cine moderno había alcanzado el éxito, en los años 80 surge como contraposición una nueva mirada, descontenta por la adopción de las tendencias de la vanguardia, pero que quiere adoptar sus formas. Se configura un cine de alusión, que hace una lectura del pasado y revisa las formas del cine clásico: es el cine posmoderno. "La unidad de este nuevo impulso -si es que la tiene- no se da en sí misma, sino en el mismo modernismo que trata de desplazar" (Jameson, 1985, p. $50)$.

Josep Picó (1998, p. 286) señala que "en el arte se llega a la imposibilidad de establecer normas estéticas válidas y se difunde el eclecticismo". Existe un gusto preferencial por la exposición de la imagen y el discurso se modifica para provocar simultaneidad y reciclaje de lo mejor de épocas pasadas.

\footnotetext{
Estas nuevas formas cobran vida mediante la apropiación y manipulación de los modelos superiores, recurriendo sistemáticamente a la imitación y mezcla de lenguajes y estilos anteriores. Aparecen como una impresión mímica del original pero sin motivo intrínsecamente ridiculizador, como una especie de ironía inexpresiva (Jameson, 1985, p. 85).
}

Jameson menciona que las primeras películas que se pueden considerar posmodernas son El gran Gatsby de Jack Clayton o Chinatown de Román Polanski, realizadas en la década del 70, allí "se trataba de establecer una nueva forma de escritura de los códigos genéricos del 
cine clásico" (Jameson, 1985, p. 85). Aunque Gutiérrez (2014, p. 297) señala que "los cineastas que realmente precedieron al cine posmoderno se encuentran en los años cuarenta con el género negro del cine clásico, un género que rompió toda esa narración de ensueño del cine clásico". Este género resulta muy poderoso en muchos aspectos, sobre todo en la oscuridad de sus protagonistas, calificados como antihéroes, la fotografía de base expresionista y el rompimiento narrativo, que a todas luces, resultó ser el detonante de todo lo que vendría después con la posmodernidad.

La publicidad y el videoclip, con sus formas de base compleja estilizada, también fueron parte del cambio. Los directores nacidos en aquellas esferas, terminaron en el cine, con lo que las películas adquirieron ese cariz que caracteriza a los videoclips: la simultaneidad, edición rápida y efectos visuales atractivos. "La visión integradora propia de la Ilustración viene sustituida por lo fragmentario, por la dispersión, por la sensibilidad hacia la diferencia y la pluralidad, por una exaltación de la subjetividad y del individualismo" (Vicente, 1999, p. 91).

\subsection{Estética del cine posmoderno: Kitsch}

A partir de lo posmoderno, se puede pensar en realidades creadas específicamente para los filmes, "el cine es así un instrumento para construir realidades que no necesariamente tienen un referente en la realidad externa al espacio de proyección" (Altman, 2000, p. 52). El fenómeno llega más allá gracias a los avances tecnológicos que crean espacios sin referente en lo cotidiano, se puede hablar de realidad virtual. En ciertas películas se puede evidenciar el artificio, y en otras el detalle llega a ser tal, que se puede perder la noción de lo que es real.

El cine posmoderno se configura también como una provocación a las estructuras narrativas clásicas, apostando siempre por la no linealidad, ruptura de lo espacio-temporal y una nueva interpretación semántica, "estructuralmente sería el filme Rashomon de Akira Kurosawa, el encargado de inaugurar un nuevo formato no lineal que llegaría a ser muy popular durante la década del noventa" (Mendoza y Cerrillo, 2003, p. 137). Lo mismo se puede decir del montaje, más complejo y artificioso, en el que se puede notar la herencia del videoclip, que apuesta por el formalismo y lo eminentemente visual.

Es necesario hacer foco en algunas de las características que ha adoptado el cine posmoderno con las distintas lecturas de lo clásico y moderno, y la valorización estética que pregona a partir de lo multifacético.
Tiene que ver con una estética formada por multiplicidad de objetos de raíz pretenciosa sin relación alguna, de mala calidad, pasado de moda y que suelen ser una copia de algún otro objeto de trascendencia, hechos para el consumo masivo. En general lo kitsch se asocia al mal gusto.

La imitación grosera de algo pasado sin que sus creaciones tengan el aliento que las hacía posibles. El estilo del kitsch difiere de las corrientes poéticas que defendieron el arte por el arte, pero solo en intensidad y en grado, pues en el kitsch es agravado con el dolo de una más penosa y fatua ostentación (González, 2015, p. 159).

De manera contraria al arte, las propuestas de la estética kitsch son masivas, sin distingo de clase social ni de nivel cultural, el nivel educativo o la cosmovisión quedan fuera para la creación y la contemplación de productos kitsch (Flores; Balderrama y Aguilera, 2016, p. 101).

Tim Burton hace uso de la estética kitsch en sus películas, en los decorados y en la exageración de sus personajes, lo que le permite crear un mundo donde se explicita el proceso de construcción de la imagen y de ello entabla una reflexión sobre sus demonios.

Una derivación del Kitsch es el Camp, "una apreciación irónica que de otra manera se consideraría tonta y pedante. Camp se deriva del término francés camper, que significa presentarse de una manera exagerada" (Calinescu, 1991, p. 281). La manera de presentar este subgénero de la comedia es mediante el gusto por la exacerbación en todo sentido y la elevación del artificio como estética formal. El director John Waters es una muestra de lo que puede hacer el camp en el cine: exageración en los diálogos, personajes excéntricos, situaciones llevadas al límite. Sus películas más destacadas en este ámbito son: Pink Flamingos, Female Trouble y Desperate Living que conforman la Trash Trilogy.

Las películas de clase B que se realizaban desde las primeras décadas del cine, caracterizadas por no tener buen renombre y una estética pobre gracias a los reducidos presupuestos de producción que obtenían, también se podrían calificar como kitsch. Plan 9 from Outer Space de Ed Wood, que en la actualidad se ha vuelto un film de culto, sería el ejemplo más emblemático de aquella manera de realizar producciones. The Room de Tommy Wiseau, calificada por muchos expertos como una de las peores películas de la historia, es otro ejemplo de películas venidas a menos y de corto presupuesto. Esta película tuvo su recuento cinematográfico en The Disaster Artist de James Franco, en la que se relatan los incidentes 
de la filmación. Existe infinidad de películas que deciden explotar las características propias de la falta de presupuesto y no luchan contra eso, sino que lo adoptan de buena manera a sus tramas y el resultado es un curioso kitsch que se ríe de sí mismo y de sus improntas.

\section{Reflexión}

\subsection{Fragmentación}

El cine ha adoptado la perspectiva posmoderna de dar sentido a la ruptura con la convencionalidad de la estructura narrativa. La fragmentación se opone a la estructura clásica aristotélica, "el criterio de composición diegética de la película no es unitario, sino que está dentro de la categoría de historias atómicas coordinadas" (Pérez, 2008, p. 6). Las construcciones contemporáneas de imágenes también pueden imitar esa sensación de división o fragmentación y esa ansia colectiva de conexión (Heternstein, 2008, p. 7). Es una característica de una gran cantidad de filmes esta alusión a la desconfiguración o a la desconexión que funciona también a nivel narrativo y que obliga al espectador a aguzar los sentidos, a fin de obtener toda la información necesaria para cerrar la historia, que también muchas veces no cierra de la manera clásica, sino que deja finales abiertos para incitar al diálogo una vez que las luces se enciendan.

Émile Durkheim habla de una "desorientación propia del hombre de la sociedad industrial, que denomina anomia o ausencia de orden significativo en la conciencia del individuo, producido por la no adhesión a un conjunto de valores comunes" (Sosa, 2008, p. 399). Por su parte, Max Weber, destaca el "alejamiento de la experiencia ordinaria de los individuos, que la perciben como algo extraño y ajeno, con el resultado de una pérdida de tradiciones vinculantes para los seres humanos. Es decir, las tradiciones pierden su significación para el individuo" (Sosa, 2008, p. 399).

En el discurso posmoderno, términos como pluralidad entran en vigencia, "la caída de la gran narrativa es una invitación directa a la cohabitación entre varias narrativas pequeñas (locales, culturales, étnicas, religiosas, ideológicas)" (Heller y Fehér, 1994, p. 153154). Tiene lugar una comunicación caótica, llena de información, que se concibe fragmentada, se cuestiona la realidad como tal y se convierte en fábula. Un ejemplo cinematográfico de este cuestionamiento de la realidad es Matrix de los Hermanos Wachowski, en donde se relata la historia del mundo como realidad virtual creada por una computadora, "en esa combinación de realidad y ficción reside la grandeza de Matrix, pues exponiendo el futuro es capaz de hablarnos del pasado y del presente" (Romero y Lozano, 2015, p. 1088). Su premisa de que somos parte de la programación de una computadora y de que el mundo en que creemos no es real, sino parte de una serie de artilugios de una gran computadora, es una extensión de las ideas de la posmodernidad. Si el gran relato es la creencia de que somos parte de una realidad creada para cegarnos y no dejarnos ver nuestra propia realidad, es una alusión a la descomposición en microrrelatos. El propio nombre del protagonista, Neo, hace alusión a lo nuevo, a lo posmoderno, y los personajes que lo acompañan, Trinity, Morpheo, en sí mismos generan ideas que apuntan a lo filosófico como discusión más profunda de las ideas. En este sentido, la película convierte su temática en universal y el género de acción que la envuelve y la adorna, queda en segundo plano.

La discusión apunta en muchos sentidos, la comunicación se emplaza como un centro categórico que debe ser analizado en cada película, el lenguaje como tal sigue esta contienda. "Con esta fragmentación del lenguaje, distintos lenguajes se liberan, estamos en un mundo de dialectos, en un mundo de valores diversos, las diferencias se liberan y los que no tenían voz pueden hablar" (Fouce, 2000, p. 61).

Jameson (1991) acota a lo anterior: "así como la angustia y la histeria eran características de la sociedad moderna, las patologías de lo esquizofrénico y la fragmentación son propias del posmodernismo". El metarrelato queda configurado en secuencias y fragmentos unidos o no por un criterio unificado, es el caso de los filmes del director mexicano Alejandro González Iñárritu, entre los que cuentan Amores perros, 21 Grams o Babel, conformados por historias paralelas que se juntan por un tema común, o por un punto de giro que cambia la vida de los protagonistas.

Snatch de Guy Ritchie, es un "filme que maneja una velocidad de yuxtaposición de situaciones y puntos de vista, acelerando el tiempo de algunas escenas, congelando el de otras y mostrando las mismas situaciones desde diversos puntos de vista" (Gil, 2002). Magnolia de Paul Thomas Anderson es una gran gama de espacios, situaciones y personajes a los que los une una idea central, así también Crash de Paul Haggis y en este último año, The ballad of Buster Scruggs de los Hermanos Coen, maneja un metarrelato compuesto de pequeñas partes sin relación aparente entre sí, unificada simplemente por el género.

El cine de Quentin Tarantino tiene en su médula el pensamiento posmoderno de la fragmentación, a modo de capítulos, como en Inglorious Basterds o Pulp Fiction, o en películas completas fragmentadas, como en Kill 
Bill Vol. 1 y 2. En cuanto a este director en particular, la violencia siempre ha sido una constante, no de forma gratuita, como él mismo lo ha asegurado en constantes entrevistas, sobre ello Molina Fox (1995, p. 154-165) menciona:

El cine violento refleja una poética del exceso que los cineastas más contemporáneos han hecho suya, distintiva. Y esa recurrencia de los comportamientos excesivos se funde naturalmente con otro valor muy propio de la estética posmoderna: la mixtura de registros.

Andrei Tarkovski juega también con las estrategias de la posmodernidad y la describe como "esa confusa situación anímica, ese empobrecimiento interior, esa incapacidad que cada vez más se va convirtiendo en irremisible característica del hombre moderno, al que se puede calificar de impotente en su interior" (Tarkovski, 1988, p. 65). Solaz recalca que el cine de este director "podría considerarse posmoderno en el sentido de que renuncia al realismo, la mimesis y las formas narrativas lineales" (Solaz, 2003, p. 6).

La manera de romper con la norma tradicional del relato también tiene que ver con el punto de vista, específicamente con la toma de decisiones. El cine juega con este concepto y relata varias de las consecuencias de las elecciones de los personajes. Es el caso de Smoking no smoking de Alain Resnais o Run Lola Run de Tom Twyker.

Por otro lado, Memento, de Christopher Nolan representa la ruptura de los cánones establecidos por la narrativa clásica, es una "típica representación de la postmodernidad, con la construcción de una identidad por medio de signos (tatuajes e imágenes fotográficas) y la fragmentación de un personaje que, aparte de un desorden patológico, sufre una crisis de identidad" (Gil, 2002). Posee estructura reversible, con un protagonista que sufre de pérdida de memoria a corto plazo.

\subsection{Muerte del sujeto}

Una de las características de la posmodernidad es su pesimismo e insatisfacción. El hecho de que nada parece llenar el vacío que genera un mundo completamente saturado de información, "cuanto más rápido nos vemos empujados hacia un futuro que no nos inspira confianza, más fuerte es el deseo de desacelerar y más nos volvemos hacia la memoria en busca de consuelo" (Huyssen, 2002, p. 165). La búsqueda de la verdad está en los microrrelatos y los sujetos se encuentran desencantados de la realidad en que viven.
El sujeto, no guiado por ningún principio sigue lógicas múltiples y contrarias entre sí, no está integrado, no es coherente, cada uno elabora a la carta los elementos que le sirven, tomando de acá y de allá, según le parece, sin preocuparse por la coherencia; se prueba y se cambia rápidamente, nada sorprende, todo vale, no hay porque aferrarse a nada demasiado tiempo (Fouce, 2000, p. 79).

El desarrollo tecnológico ha provocado un acceso inusitado a la información, mayores posibilidades de comunicación y el resultante ha sido un individuo encerrado en sí mismo y en los aparatos que maneja. Lyotard menciona al respecto: "El sujeto es un producto de la máquina de representación y desaparece en ella" (2004, p. 121).

El cine de la posmodernidad hace alusión a este hecho y lo resalta en la creación de sus personajes. David Lynch en sus películas transforma elementos heterogéneos, juega con la forma y el fondo, y genera una nueva realidad. Rabbits es una muestra de esa toma de conciencia de la creación como la concibe el surrealismo, un filme sin ataduras, sin convenciones narrativas, que salpican a toda su obra, en ese mundo conviven personajes perturbados, presos de aquella realidad en que les ha hecho vivir el director. Magnolia de Paul Thomas Anderson en sus relatos fragmentados, también nos muestra esta agonía del sujeto que vive por los azares del destino, no existen explicaciones para ciertos fenómenos y los sujetos tienen marcado su futuro.

Fight Club, de David Fincher, es una crítica al status quo, un hombre enajenado, que se ha dado cuenta de la realidad en la que vive y resulta tan coherente en su locura. Es un prototipo del anti-héroe de las historias posmodernas, afectado por una disociación de la personalidad: por un lado, convive el yo consumista y su opuesto, un hombre que lo cuestiona todo. No country for old men de los Hermanos Coen, nos brinda el personaje Anton Chigurg (Javier Bardem), un antagonista por antonomasia, que reflexiona de manera nihilista a lo largo de todo el metraje como una bala perdida que conforma sus propias verdades. La reflexión de Magallón (2013, p. 312) se ajusta a la creación de este personaje:

Una razón sin sujeto es una racionalidad que no implica responsabilidad ni compromiso, sino una idea que se diluye en un individualismo extremo, sin ética ni compromiso social, sin política, y, en la medida en que no hay responsable, pierde su razón de ser.

En el mismo film, Tom Bell (Tommy Lee Jones), es el sheriff de edad avanzada que cuestiona la manera en que el mundo está cambiando a su alrededor, la maldad y la 
desapropiación del sujeto, de gente que ya no se preocupa por los demás y donde los valores morales están por los suelos. "En este modelo posmoderno, el individuo está solo, librado a su propia suerte, sin la protección que le otorgaba el Estado benefactor y sin las previsiones sociales y laborales, que le garantizaban una calidad de vida mejor" (Carenzo, 2005, p. 60). Esta es una película que fue analizada desde todas sus aristas y considerada a ser objeto de estudio de la academia, pues el foco no solo lo tiene puesto sobre los personajes, sino sobre todo el entramado que significa la creación de un filme.

\subsection{Intertextualidad y pastiche}

En la época posmoderna, todos los relatos pueden combinarse para crear uno nuevo, lo que hace que los elementos tomados de la obra primigenia, pierdan su significado inicial, su simbolismo y soporte histórico, para quedarse con la forma y ser adheridos en una especie de collage en una nueva obra, que los adopta a manera de homenaje.

La intertextualidad ha de entenderse como el conjunto de relaciones que acercan un texto determinado a otros textos de varia procedencia: del mismo autor o más comúnmente de otros, de la misma época o de épocas anteriores, con una referencia explícita (literal o alusiva) o la apelación a un género, a un arquetipo textual o a una fórmula imprecisa o anónima (Rodríguez-Ferrándiz, 2001, p. 1).

La cita, referencia, parodia, pastiches, ironías, comentarios son parte de la intertextualidad, en la que todo tipo de imágenes, textos, estructuras, géneros y demás se entrecruzan para dar lugar a una nueva obra. "Las estrategias intertextuales de toda estética de ruptura son la parodia y la meta-ficción. La primera tiene una naturaleza irónica $[\ldots]$ y la segunda pone en evidencia las fronteras entre la realidad y las convenciones de toda representación" (Agirre, 2014, p. 8).

Para que el recurso tenga sentido, se entiende que la obra de base debe proporcionar el código de interpretación, pues de otra manera, el intertexto perdería sentido. "Cuando se está citando, se toma distancia de lo que se cita y al mismo tiempo se lo incorpora; se está realizando un movimiento de apropiación y de entrega, y también una aventura, un salto al vacío" (Jitrik, 1993, p. 13). Carrol ha definido esto como cine de alusión que tiene mayor funcionalidad sobre quienes han visto mucho cine y pueden interpretar las referencias.

Ciertos homenajes en forma de recreaciones de escenas clásicas, así como el uso de leitmotivs, personajes tipo, tramas, gestos y líneas de diálogo que hayan pasado a la historia del cine. Ciertas películas de Woody Allen son un buen ejemplo (Carroll, 1998, p. 241).

The Darjeeling limited de Wes Anderson es un ejemplo de referencia a un cine por completo, pues representa a lo largo de toda su historia al cine de la India y al filme Le fleuve de Jean Renoir, puntualmente en las experiencias de occidentales en la India. Lo mismo ocurre con el filme Tacones Lejanos de Pedro Almodóvar, que resulta ser un homenaje a la película Höstsonaten de Ingmar Bergman.

Como señala David Bordwell: "una estructura realista basada en el cine dentro del cine motiva referencias a otras obras, permite cambios inesperados entre niveles de ficcionalidad y puede desencadenar ocasionalmente la parodia del propio arte cinematográfico" (1996, p. 213). Una de las variaciones de la intertextualidad es el pastiche.

Pastiche se puede definir como "imitación o plagio que consiste en tomar determinados elementos característicos de la obra de un artista y combinarlos de forma que parezcan una creación original" (Vaskes, 2011, p. 64). Así estilos, géneros, personajes, estructuras, dialogan entre sí y se reelaboran para crear un nuevo producto. Este dialogo puede generar incluso una discusión crítica sobre lo que se está mirando y el por qué ha sido incluido como parte del metraje, puede ser en muchos casos una ironía acerca de la realidad, «el recurso irónico funciona en la imitación de los elementos conocidos y en la reutilización de éstos con un resultado distinto» (Jameson, 2002, p. 93).

Quentin Tarantino es un ejemplo de filmes que incluyen pastiche. En su película Kill Bill existe una bifurcación de elementos adoptados del anime, el cine de artes marciales, el comic y directos homenajes al cine de Sergio Leone, Sam Peckinpah y Akira Kurosawa. Otro gran detalle en su filmografía es el uso de la música, utilizada a manera de collage que podría resultar un sinsentido en otras manos.

Pulp Fiction, del mismo director, es otro filme de pastiche, en su estructura narrativa alude a The Killing de Stanley Kubrick, The Life and Death of Colonel Blimp de Michael Powell y Emeric Pressburger, y Once upon a time in América de Sergio Leone, esta última, referente de base para su última película Once upon a time in Hollywood. Todo parece ser una relectura del pasado, y realmente así resulta, en la posmodernidad, la intertextualidad funciona como un elemento creativo que no llega a ser considerado plagio y más bien resalta las bondades de quienes crean de esta manera. Claro está que en pocas ocasiones el recurso es validado como un aporte a la historia, pues en la mayoría de ocasiones, resulta en una herramienta de alusión o parodia sin ninguna significación, que más bien 
empobrece el relato.

\subsubsection{Intergenericidad}

La intergenericidad es el diálogo entre géneros cinematográficos para derivar en una nueva obra, así se retoma géneros que han dejado de ser populares y se les otorga nuevos sentidos. En sí, el hecho provoca artificialidad, pues recrear la convención provoca exceso estilístico, que culmina en obras con más o menos peso reflexivo.

Un ejemplo de ello es el western, un género utilizado por los norteamericanos para describir la épica del país y sus valores. Los vaqueros pasan a ser una especie de superhéroes que tienen un destino prestablecido y una iconografía que destaca: ponchos, pistolas, desiertos, caballos, ranchos, etc. El culmen es una escena grandiosa de enfrentamiento entre protagonista y antagonista; toda la película prepara ese momento final.

Los hermanos Coen han trabajado con la mixtura de géneros y es algo que se aprecia en sus películas, aunque hay algunas específicas que tratan de ser puritanas en su concepción de lo que debe ser el cine negro, es el caso de Miller's Crossing. En su última película, The ballad of Buster Scruggs, se ve en muchos episodios el detalle marcado para recrear el género y el valor de la épica y lo estilizado.

Géneros como el musical han tenido éxito en los últimos tiempos. La $\mathrm{La}$ Land de Damien Chazelle es una asimilación del género con homenajes sostenidos y reflexivos. En este nuevo milenio, varios ejemplos de musicales también han salido a la luz como Moulin Rouge de Baz Luhrmann, Caravaggio de Derek Jarman, o Chicago de Rob Marshall.

En Moulin Rouge existe una serie de reminiscencias tanto al musical como al vodevil europeo, la cultura del cabaret, los musicales teatrales y la ópera. One from the Heart de Francis Ford Coppola, nos remonta a este género, "Coppola encuentra allí un repertorio de formas y una colección de rasgos fetiches, como la necesidad del canto y del baile, elementos definitorios del género" (SánchezBiosca, 1995, p. 133).

Existen multiplicidad de películas contemporáneas que han hecho un uso conciente de los géneros y de sus mixturas para lograr películas que respeten los cánones y, a la vez, se vean novedosas. Blade Runner de Ridley Scott, o Pulp Fiction de Quentin Tarantino adoptaron códigos genéricos del cine negro y el pulp, para recontextualizarlos y darles un nuevo valor. Seven de David Fincher, un thriller actual con el estereotipo del policía a punto de retirarse y el nuevo policía loco por hacer justicia, dos partes de un solo personaje. Scream de Wes Craven remitiendo al género de terror; Mars Attacks de Tim Burton, parodia del cine de catástrofes, homenaje al cine serie B y a la ciencia ficción más tradicional.

\subsubsection{Remake}

El remake es volver a hacer una misma historia variando ciertos detalles, tanto en la trama como en los personajes, para adaptarlos a la actualidad. La exacerbación del remake es un síntoma de la falta de originalidad que aqueja a Hollywood, toma éxitos precedentes para asegurar un mínimo de taquilla, quitando espacio a historias nuevas y novedosas, que han debido cambiar de formato e irse a la televisión. Muchos de los éxitos de Disney prefieren no arriesgar los grandes montos de dinero que ponen en sus producciones, plagadas de efectos especiales.

Otra tónica de Hollywood es tomar historias que tuvieron éxito en otras regiones del mundo y hacer un remake con sus propias figuras, de esto deriva Vanilla Sky de Cameron Crow, remake de Abre los ojos, de Alejandro Amenábar; Der Himmel über Berlin, de Win Wenders y City of Angels, de Brad Silverling; Ocean's Eleven de Lewis Milestone, y Ocean's Eleven de Steven Soderbergh; Scarface de Howard Hawks y la homónima de Richard Rosson; Psicho de Alfred Hitchcock y la versión calcada de Gus Van Sant; El secreto de sus ojos de Juan José Campanella y Secret in Their Eyes de Billy Ray y el caso curioso de Funny Games de Michael Haneke, que dirigió la versión alemana y norteamericana.

\section{Conclusión}

En relación a la tesis planteada en la introducción del presente estudio, se puede decir que la posmodernidad toma forma cuando se revela contra la modernidad, cuando se enfrenta al metarrelato y a la complacencia de los discursos totalizadores, se muestra en la artificialidad, en lo fragmentario y en el ensueño que provoca la visita al pasado.

El cine posmoderno es una derivación de las ideas propias del paradigma posmoderno, que plantea la muerte del sujeto y una imagen pesimista de la realidad, existen ejemplos variopintos de esto, algunos con mejores resultados que han pasado a los anales de la historia como clásicos instantáneos. Hay otros que se regocijan en la autocomplacencia y que por medio de la intertextualidad logran una permeabilidad de narrativas, géneros y personajes, provocando un collage sin sentido que busca recaudar en taquilla. 
Cambridge: Cambridge University Press.

La intertextualidad provoca ensueño, porque la visita al pasado siempre es un aliciente que traspasa fronteras y no es solo un guiño, sino que se retoman géneros completos, películas, formatos, personajes y narrativas, se reciclan estilos y contextos, incluso de otros artes. En todo caso, esto no siempre resulta en obras de arte o ensayo, sino en elementos dispares que extraen la imagen primigenia y la exprimen de su sentido, para apelar a los sentimientos de los espectadores, que se encontrarán con grandes recuerdos de toda índole.

Desde su inicio en los años 80, el cine posmoderno no ha parado de realizar filmes, utilizando infinidad de variaciones con resultados memorables, clásicos instantáneos y otros que han quedado en el olvido. Directores posmodernos han quedado para la historia, haciendo uso del eclecticismo, el pastiche, el relato no lineal, la fragmentación o el cuestionamiento de la realidad, para verse sumidos en un reflejo de las reflexiones teóricas y filosóficas que se han hecho sobre la posmodernidad, un reflejo que se regocija en el exceso, lo estilístico y popular.

\section{Referencias}

1. Agirre, K. (2014). El nuevo Hollywood y la posmodernidad: entre la subversión y el neoconservadurismo. Palabra Clave, 17 (3), 645671. DOI: 10.5294/pacla.2014.17.3.4

2. Altman, R. (2000). Los géneros cinematográficos. Barcelona: Paidós.

3. Aumont, J. (1995). Estética de cine. Barcelona: Paidós.

4. Best S. y Douglas K. (1991). Postmodern Theory. Critical Interrogations. Estados Unidos: Guilford Press.

5. Bordwell, D. (1996). La narración en el cine de ficción. Segunda Edición. Barcelona: Editorial Paidós.

6. Calinescu, M. (1991). Cinco caras de la modernidad: modernismo, vanguardia, decadentismo, kitsch, posmodernismo. Editorial Tecnos, Madrid-España.

7. Carenzo, R. (2005). La posmodernidad. Revista Tiempo de Gestión. 1(1). 57-66.

8. Carroll, N. (1998). Interpreting the moving image.
9. Casetti, F. y Chio F. (1991). Como analizar un film. Buenos Aires-Argentina.

10. Carretero, E. (2000). Posmodernidad y temporalidad social. Cuarta Edición. Editorial Paidós. 2000.

11. De Carvalho, José. (1994). La antropología y el nihilismo filosófico posmoderno. Revista Alteridades, 4(8), 13-29.

12. De la Rosa, R. (2000). Que es posmodernidad. Segunda Edición. Ediciones San Pablo, MadridEspaña.

13. Flores, J; Balderrama, C; Aguilera G. (2016). El entorno cotidiano, la estética kitsch y su relación con los diseños. Nóesis. Revista de Ciencias Sociales y Humanidades, 25(49), enero-junio, 98-120. Instituto de Ciencias Sociales y Administración Ciudad Juárez, México.

14. Fouce J. (2000). Frente a la posmodernidad. Fundamentos en Humanidades, vol. I, (2), diciembre, 55-77. Universidad Nacional de San Luis San Luis, Argentina.

15. González, I. (2015). Valor y kitsch en la Muerte de Virgilio. $452^{\circ} \mathrm{F}$. (12). 154-166.

16. González, L. (1991). Ideas y creencias del hombre de hoy. Madrid: Sal Terrae.

17. Gutiérrez, M. (2014). El cine de autor del cine moderno al cine posmoderno (Colombia). Razón y Palabra. Primera Revista Electrónica en Iberoamérica Especializada en Comunicación. (87) Investigación en comunicación aplicada.

18. Hertenstein, M. (2008). Introduction: Cinema in the Biblical Sense. En Morefield, K. (ed.) Faith and Spirituality in Masters of World Cinema. 8-20. Cambridge: Cambridge Scholars Publishing.

19. Huyssen, A. (2002). En busca del futuro perdido. Cultura y memoria en tiempos de la globalización. México: Paidós.

20. Jameson, F. (1991). Posmodernismo y sociedad de consumo. Barcelona: Kairós.

21. Jameson, F. (2002). El giro cultural. Buenos Aires: 
Manantial.

22. Jameson, F. (1991). El posmodernismo o la lógica cultural del capitalismo avanzado. Barcelona: Paidós.

23. Jitrik, N. (1993). Rehabilitación de la parodia. Buenos Aires: Instituto de Literatura Hispanoamericana, UBA.

24. Lyon, D. (1996). Posmodernidad. Barcelona: Alianza Editorial.

25. Lyotard, J. (2004). La Condición Posmoderna. Barcelona: Cátedra.

26. Magallón, M. (2013). El problema del sujeto en la posmodernidad occidental. Análisis. Revista Colombiana de Humanidades, (83). 381- 408. Universidad Santo Tomás Bogotá, Colombia.

27. Mendoza A. y Cerrillo P. (2003). Intertextos, aspectos sobre la recepción del discurso artístico. Castilla: Ediciones de la Universidad de Castilla.

28. Molina Fox, V. (1995). El cine posmoderno: un nihilismo ilustrado. Madrid: Cátedra.

29. Pérez Marín, D. (2008). 71 fragmentos de una cronología del azar de Michael Haneke. La glaciación de los sentimientos en la sociedad fragmentada. Frame: revista de cine de la Biblioteca de la Facultad de Comunicación. (3). 283-295.

30. Picó, J. (1998). Modernidad y postmodernidad. Madrid: Alianza.

31. Ramírez A. (2005). Posmodernidad y política. Revista Espiga. (12). 109-118. Universidad Estatal a Distancia San Pedro de Montes de Oca, Costa Rica.

32. Rodríguez-Ferrándiz, R. (2003). Publicidad omnívora, publicidad caníbal: el intertexto polémico. I Jornadas de Publicidade e Comunicação, Universidade da Beira Interior (Covilha, Portugal)LabCom.

33. Romero Sánchez-Palencia, Carmen; Lozano Díaz, Vicente. Actualización docente: la postmodernidad y la película de Matrix. Opción, vol. 31, núm. 3, 2015, pp. 1086-1103 Universidad del Zulia. Maracaibo, Venezuela. Disponible en: https://www. redalyc.org/pdf/310/31045567057.pdf
34. Ros Cherta J. (S/A). Gilles Lipovetsky o El culto a lo privado. Recuperado de: http://www.raco.cat/ index.php/RecercaPensamentAnalisi/article/ viewFile/106332/153051. 17 de julio de 2019.

35. Sánchez-Biosca, V. (1995). Una cultura de la fragmentación. Pastiche, relato y cuerpo en el cine $y$ la televisión. Valencia: Paidós.

36. Sangro, P. (2016). Las vanguardias artísticas del siglo XX y su contribución teórica en la definición exhibicionista de la naturaleza del cine. Anagramas Rumbos y Sentidos de la Comunicación, 14(28). Universidad de Medellín. Universidad Pontificia de Salamanca, España.

37. Solaz, L. (2003). Cine Postmoderno. Revista En Cadena Dos, (39). Recuperado el 14 de julio de 2019 de http:// www.encadenados.org/n39/cine postmoderno.html

38. Sosa, R. (2008). Una reflexión sobre la noción de fragmentación en la sociedad de cambio de siglo. Revista de Antropología Experimental. No 8(28). 397-401. Universidad de Jaén. Universidad Complutense de Madrid.

39. Sousa S. (2005). El milenio huérfano. Madrid: Trotta.

40. Tarkovski, A. (2002). Esculpir en el Tiempo. Reflexiones sobre Arte, la Estética y la Poética del cine. Madrid: RIALP Ediciones.

41. Vaskes, I. (2011). Posmodernidad estética de Frederick Jameson: pastiche y esquizofrenia. Praxis Filosófica. (33). 53-74 Universidad del Valle Cali, Colombia.

42. Vattimo, G. y Rovatti P. (2006). El pensamiento débil. Madrid: Cátedra.

43. Vicente, A. (1999). El arte en la postmodernidad. Todo vale. Barcelona: Drac.

44. Vrolijk, C. (2002). Estructuras no lineales en la narrativa (literatura, cine y medios electrónicos). Pontificia Universidad Javeriana. Facultad de Ciencias Sociales. Departamento de Literatura. Bogotá-Colombia. 